\title{
Matemática para Alunos Autistas, um Estudo Sobre a Utilização de Ferramentas Tecnológicas no Processo de Ensino e Aprendizagem
}

\author{
Anderson Daniel Stochero ${ }^{1}$, Bruna Willig Kopplin', Cristiane da Silva Stamberg', \\ Andréa Pereira ${ }^{1}$ \\ ${ }^{1}$ Instituto Federal de Educação, Ciência e Tecnologia Farroupilha - IFFAR (campus \\ Santo Ângelo) Caixa Postal 15.064 - 91.501-970 - Santo Ângelo - RS - Brazil
}

anderson_stochero@yahoo.com.br, brunawkopplin@gmail.com, \{cristiane.stamberg, andrea.pereira\} @iffarroupilha.edu.br

\begin{abstract}
This article discusses the development of a research project based on the proposal of games and didactic materials creation through the use of software and technological tools, in order to contribute to the process of teaching and learning in mathematics of young people with autism spectrum disorder. The study is in phase of research and analysis of the factors and other aspects related to the characteristics of the subject, through interviews with professionals of the area, educators, associations and the subjects of the research. The next step is to identify the most appropriate tools and create the proposed items.
\end{abstract}

Resumo. Este artigo aborda o desenvolvimento de um projeto de pesquisa baseado na proposta de criação de jogos e materiais didáticos através da utilização de softwares e ferramentas tecnológicas, a fim de contribuir com o processo de ensino e aprendizagem em matemática de jovens com transtorno do espectro autista. O estudo encontra-se em fase de pesquisa e análise dos fatores mais relevantes acerca das características do sujeito autista, através de entrevistas com profissionais da área, educadores, associações e os próprios sujeitos da pesquisa. O próximo passo se estabelecerá com a identificação das ferramentas mais adequadas e criação dos itens propostos.

\section{Introdução}

$\mathrm{O}$ direito do aluno com necessidades educativas especiais e de todos os cidadãos à educação é um direito constitucional. A garantia de uma educação de qualidade para todos implica, dentre outros fatores, um redimensionamento da escola no que consiste não somente na aceitação, mas também na valorização das diferenças. Esta valorização se efetua pelo resgate dos valores culturais, os que fortalecem identidade individual e coletiva, bem como pelo respeito ao ato de aprender e de construir [Jacomeli 2017].

No atual contexto social a inclusão tornou-se imprescindível, e necessária de ser estudada e trabalhada dentro e fora das instituições de ensino. Sendo assim, este artigo tem como objetivo apresentar as ações desenvolvidas a partir de um projeto de pesquisa que possui como proposta encontrar caminhos para a utilização de ferramentas tecnológicas capazes de contribuir com processo de ensino e aprendizagem da matemática para alunos com transtorno do espectro autista, possibilitando a promoção 
de aprendizagens significativas para um maior número possível de pessoas no ambiente escolar.

Quanto ao aprendizado da matemática e das ferramentas tecnológicas mais adequadas, estão sendo realizados estudos, para que a criação de jogos e materiais didáticos se torne passível de contribuição com o aprendizado, inclusão e a integração de crianças autistas no ambiente educacional. O conjunto desses dados, associados à fundamentação teórica permite reflexões e análises das percepções, e ações a serem assumidas, apropriando-se das dificuldades, barreiras, trabalhos bem-sucedidos, e desenvolvidos pelas escolas que possuem alunos portadores de alguma necessidade específica.

\section{Contextualização}

Diante dos problemas e dificuldades enfrentados ao longo do processo de ensino e aprendizagem os educadores sentem, cada vez mais, à necessidade de recorrer a ferramentas capazes de auxiliar neste processo. Nesse sentido, torna-se urgente buscar aporte das tecnologias da informação, as quais oferecem subsídios capazes de suprir tais carências. Conforme destaca [Jucá 2006], por muitos anos o quadro e o giz foram utilizados como as principais ferramentas de ensino na mediação pedagógica, porém, nas últimas décadas a difusão da tecnologia vem se propagando e tomando conta das instâncias educacionais. Foi a partir da união da tecnologia com os meios de comunicação que ocorreu a revolução da educação, possibilitando novas experiências de aprendizado através da utilização de softwares específicos trabalhados no contexto de ensino e aprendizagem, os quais são denominados softwares educacionais.

Neste contexto [Morellato et al. 2006] defendem que a utilização da informática na educação se apresenta como uma importante ferramenta no processo de aprendizagem assumindo diversos significados. Desta forma, não basta inserir hardwares e softwares no ambiente educacional, é de suma importância que a escola reflita acerca de sua utilização e na promoção significativa de aprendizagem de modo que o sujeito seja capaz de desenvolver e executar algo de forma que a construção do conhecimento ocorra através da resolução de problemas e da comunicação.

$\mathrm{Na}$ verdade, o educador desempenha um papel fundamental neste processo de forma que se faz necessário adicionar novas exigências em seu perfil, a fim de atender tais mudanças, como: saber lidar com os ritmos individuais dos alunos, se apropriar de novas técnicas para a produção de materiais didáticos através dos meios eletrônicos, diferente daqueles do ensino tradicional, manejando de forma criativa as novas tecnologias [Jucá 2016]. Há a necessidade de mudanças na postura no processo de ensino e aprendizagem de acordo com a necessidade de cada indivíduo, com isso buscando novas abordagens na prática pedagógica, entre elas a utilização de recursos da informática, possibilitando a maior participação dos alunos em geral. Afirma-se também que o ambiente de aprendizagem baseado nas tecnologias da informação e comunicação proporcionam atividades com propósitos educacionais favorecendo a construção do conhecimento e proporcionando ao aluno novas experiências.

Nesta perspectiva, legitima-se o desenvolvimento desse projeto de pesquisa, pois há uma intencionalidade em proporcionar ao aluno novas experiências de ensino e aprendizagem e também promover a inclusão de jovens no ambiente educacional, diante do reconhecimento da importância na utilização da tecnologia nesse processo, 
trabalhando com o desenvolvimento jogos e materiais didáticos voltados para indivíduos com transtorno do espectro autista.

De acordo com [Bosa 2016] o autismo pode ser classificado como um transtorno invasivo do desenvolvimento e abarca algumas dificuldades ao longo da vida do portador afetando as habilidades sociais e comunicativas além de comportamento e interesses limitados e repetitivo. De forma geral, a maioria dos jovens autistas apresentam dificuldades de compreensão de linguagem abstrata ou dificuldade de lidar com sequências complexas de instruções que necessitam ser decompostas em unidades menores. Sendo assim, para auxiliar no processo de inclusão e aprendizagem dos indivíduos autistas, é comum a utilização de softwares e hardwares para facilitar a assimilação do conhecimento, apesar de não haver grande quantidade softwares apropriados para o grupo em questão, de forma que atenda às necessidades baseando nas características do espectro autista. Contudo, nos últimos anos têm sido comprovada a eficiência da utilização de softwares e hardwares assistivos no desenvolvimento cognitivo e melhoria de habilidades de jovens autistas [Souza et. al. 2016].

\section{Metodologia}

O desenvolvimento do projeto foi baseado inicialmente em referenciais bibliográficos, e após, submetido ao comitê de ética, para que se tornasse possível a continuidade da pesquisa.

No que se refere às entrevistas com pessoas especializadas, foi estabelecida a metodologia de entrevista semiestruturada, a qual compreende um roteiro com perguntas fechadas e abertas, permitindo maior flexibilidade nas conversas e para o entendimento questões trazidas pelo interlocutor. Esse modelo favorece a comunicação entre entrevistador e entrevistado possibilitando aprofundar as reflexões em torno de determinado tema [MINAYO 2010]. Os participantes das entrevistas, já atuam em uma perspectiva de inclusão, profissionais da educação e gestores, articulados com o uso da tecnologia no ensino e aprendizagem de matemática, com intuito de conhecer a realidade e as necessidades no processo de ensinar e aprender do sujeito com autismo. As instituições visitadas e entrevistadas no primeiro momento foram: Associação de pais e amigos do autista e centro de atenção psicossocial infância e adolescência (CAPSI II).

\section{Resultados e Discussão}

O contato inicial se estabeleceu com um profissional fisioterapeuta com estudos sobre o autismo. A entrevista possibilitou expandir os conhecimentos sobre as principais características dos jovens autistas, possibilitando uma reflexão mais aprofundada e norteando os passos a serem traçados para o desenvolvimento do projeto.

Outro encontro que merece destaque foi na instituição CAPSI II, de forma que no primeiro contato houve a possibilidade de participar de uma reunião com a coordenadora e mais cinco psicólogas que atendem crianças com autismo, objetivando expor o projeto em desenvolvimento e conhecer mais das características do público-alvo deste estudo. As psicólogas relataram os trabalhos e as atividades que realizam com as crianças e orientaram quanto ao nível de jogo a ser implementado, destacando que o mais adequado para se trabalhar matemática é com as etapas iniciais como por exemplo: as quatro operações básicas. Foi agendado, também, um encontro no laboratório de 
informática da instituição, com crianças previamente selecionadas pelas psicólogas para mostrar alguns softwares existentes voltados ao ensino da matemática com a finalidade de analisar o comportamento e a aceitação das crianças quanto a aplicabilidade de softwares de jogos.

\section{Considerações finais}

A partir do desenvolvimento do presente projeto espera-se como resultado a efetiva melhoria no processo de ensino e aprendizagem em matemática, através de jogos e materiais didáticos desenvolvidos com o auxílio de ferramentas tecnológicas, tendo como foco alunos com transtorno do espectro autista. Acredita-se que promover a inclusão com o apoio de softwares que contemplam jogos e materiais didáticos se apresenta como uma relevante contribuição para o campo da educação. Espera-se também revelar o potencial das tecnologias no cotidiano das instituições de ensino, como um recurso pedagógico fundamental, merecedores de maior reconhecimento, rompendo com as metodologias tradicionais e sensibilizando profissionais envolvidos no campo da educação, especialmente os que atuam com pessoas que possuem necessidades educacionais diferenciadas.

Atualmente o projeto encontra-se na fase de investigação, realizando entrevistas com profissionais das áreas relacionadas, associações de pais e com os indivíduos foco deste estudo, visando identificar as necessidades de cada um, seus gostos e peculiaridades, permitindo assim, avançar para as próximas etapas, que se estabelece na seleção e construção de jogos e materiais didáticos com o auxílio de softwares e ferramentas tecnológicas, a fim de contribuir para o processo de ensino e aprendizagem da matemática, componente curricular obrigatório na educação básica brasileira.

\section{Referencias}

Bosa, C. A. (2016) "Autismo: Intervenções Psicoeducacionais", http://dx.doi.org/10.1590/S1516-44462006000500007, Março.

Jacomeli, R. B. (2017) "A Inclusão de Alunos com Necessidades Especiais no Ensino Regular", http://meuartigo.brasilescola.uol.com.br/educacao/a-inclusao-alunos-comnecessidades-especiais-no-ensino-regular.htm”, Março

Jucá, S. C. S. (2016) "Relevância do Software Educativo na Educação Profissional", http://cienciasecognicao.org/pdf/v08/cec_vol_8_m32689.pdf, Março.

Minayo, M. C. S. (2010) "O desafio do conhecimento: pesquisa qualitativa em saúde." 12. ed. São Paulo: Hucitec.

Morellato, C. et al (2016) "Softwares Educacionais e a Educação Especial: Refletindo sobre aspectos pedagógicos", http://seer.ufrgs.br/index.php/renote/article/view/13887/7803, Março.

Sousa, F. R. M.et. al. (2016) "WorldTour: Software para Suporte no Ensino para Crianças Autistas", http://www.br-ie.org/pub/index.php/sbie/article/view/1806/1567, Março.

Zulian, M. S. F, Soraria N. (2016) "Formação de Professores na Educação Inclusiva: Aprendendo a Viver, Criar, Pensar e Ensinar de Outro Modo", http://coralx.ufsm.br/revce/ceesp/2001/02/r5.html, Março. 